\title{
Treatment research
}

\section{Applications of transcranial magnetic}

stimulation and magnetic seizure therapy

in the study and treatment of disorders

related to cerebral aging

Bruce Luber, PhD; Shawn M. McClintock, PhD; Sarah H. Lisanby, MD

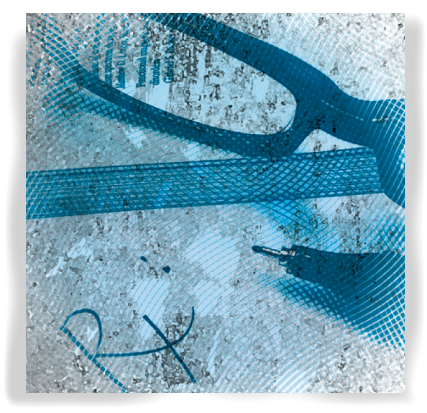

Transcranial magnetic stimulation (TMS) can be used to probe cortical function and treat neuropsychiatric illnesses. TMS has demonstrated neuroplastic effects akin to longterm potentiation and long-term depression, and therapeutic applications are in development for post-stroke recovery, Alzheimer's disease, and depression in seniors. Here, we discuss two new directions of TMS research relevant to cerebral aging and cognition. First, we introduce a paradigm for enhancing cognitive reserve, based on our research in sleep deprivation. Second, we discuss the use of magnetic seizure therapy (MST) to spare cognitive functions relative to conventional electroconvulsive therapy, and as a means of providing a more potent antidepressant treatment when subconvulsive TMS has shown modest efficacy in seniors. Whether in the enhancement of cognition as a treatment goal, or in the reduction of amnesia as a side effect, these approaches to the use of TMS and MST merit further exploration regarding their clinical potential.

(C) 2013, LLS SAS

Dialogues Clin Neurosci. 2013;15:87-98.

Keywords: transcranial magnetic stimulation; TMS; magnetic seizure therapy; MST; neuroplasticity; aging; neuroscience

\author{
Introduction
}

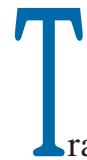
niques that has been in development over the last few decades. Noninvasive brain stimulation has two areas of functionality. First, it can serve as a means of perturbing the brain, and the consequences of that perturbation can be observed via subsequent behavioral performance, subjective experience, or brain imaging and electrophysiological measures. This allows TMS to be used both experimentally as a means of exploring neural function and clinically as a diagnostic and therapeutic tool. TMS has the great strength of allowing brain/behavior relationships to be established causally, rather than just as a correlation, as in the case in brain imaging. Second, because it can modulate brain function, it has the potential of acting as a treatment for neuropsychiatric diseases. In this regard, repetitive TMS was approved by the United States Food and Drug Administration (US FDA) for the treatment of major depressive disorder (MDD), and has been reported to hold promise for other neuropsychiatric disorders including bipolar disorder, schizophrenia, obsessive-compulsive disorder, and other conditions. ${ }^{1}$

Author affiliations: Departments of Psychiatry and Behavioral Sciences (Bruce Luber, Shawn McClintock, Sarah H. Lisanby) and Psychology and Neuroscience (Bruce Luber, Sarah H. Lisanby) Duke University, Durham, North Carolina, USA; Department of Psychiatry, UT Southwestern Medical Center, Dallas, Texas, USA (Shawn McClintock)

Address for correspondence: Bruce Luber, PhD, Brain Stimulation \& Neurophysiology Division, Department of Psychiatry and Behavioral Sciences, Duke University Medical Center Box 3620, Durham, NC 27710, USA (e-mail: bruce.luber@duke.edu) 


\section{Treatment research}

\section{Selected abbreviations and acronyms}

$\begin{array}{ll}\boldsymbol{A D} & \text { Alzheimer's disease } \\ \boldsymbol{L T D} & \text { long-term depression } \\ \boldsymbol{L T P} & \text { long-term potentiation } \\ \boldsymbol{M E P} & \text { motor evoked potential } \\ \boldsymbol{M S T} & \text { magnetic seizure therapy } \\ \boldsymbol{P A S} & \text { paired associate stimulation } \\ \boldsymbol{P D} & \text { Parkinson's disease } \\ \boldsymbol{R T} & \text { reaction time } \\ \boldsymbol{r T M S} & \text { repetitive transcranial magnetic stimulation } \\ \boldsymbol{S D} & \text { sleep deprivation } \\ \boldsymbol{T M S} & \text { transcranial magnetic stimulation }\end{array}$

TMS is a noninvasive method of focally altering cortical brain activity. ${ }^{2}$ A TMS device emits brief pulses of current through a stimulating coil held on the head. The current flow lasts less than a millisecond and produces a rapidly changing magnetic field around the coil. This magnetic field in turn induces current flow in cortical tissue near the surface of the head that stimulates neurons in a focal region and modulates neural activity. The magnetic field exponentially decreases in strength with distance as it passes unobstructed through the skull and brain tissue, effectively depolarizing neurons up to approximately $2 \mathrm{~cm}$. The effects are not entirely local, as the depolarized neurons transmit their activity transynaptically to connected subcortical and transcortical regions within functional networks. The actual neurobiologic effects depend on factors such as the intensity of the magnetic field, the coil shape and its orientation, and the geometry of the underlying cortex in relation to the magnetic field.

\section{Neuroplastic effects of TMS}

The neural effects of TMS depend on the frequency of stimulation. When the frequency of TMS stimulation is $1 \mathrm{~Hz}$ or greater, the stimulation is called repetitive TMS (rTMS). If rTMS is pulsed at a low frequency (about 1 $\mathrm{Hz}$ ), cortical excitability generally decreases, while higher-frequency rTMS can increase cortical excitability, ${ }^{3}$ though there are exceptions to this general rule. The modulation of cortical excitability with rTMS lasts beyond the stimulating train; typically, the effects of a series of rTMS trains applied over a 10- to 30-minute period lasts between approximately 10 and 60 minutes. ${ }^{4,5}$ This up- or downregulation of cortical excitability extended beyond the period of stimulation demonstrates the ability of TMS to affect cortical plasticity. The ratedependent nature of this modulation is reminiscent of long-term potentiation and long-term depression (LTP and LTD, respectively), which represent the leading models for the physiological basis of plasticity and memory, developed by studying the effects of electrical stimulation of hippocampal slices of animals. ${ }^{6}$ High-frequency $(5$ to $15 \mathrm{~Hz}$ ) stimulation trains that increased the excitability of granule cells from the dentate gyrus for periods from 30 minutes to 10 hours provided the first evidence of LTP. ${ }^{7}$ LTP- and LTD-like plasticity effects have been found noninvasively in humans with TMS through examination of motor evoked potentials (MEPs) generated from stimulation of the primary motor neurons. ${ }^{4,8,9}$

Converging evidence using a number of different paradigms has substantiated that TMS can result in synaptic changes in cortical neurons..$^{10,11}$ A particular method, paired associate stimulation (PAS) has been well studied. ${ }^{10}$ In PAS, the median nerve in the forearm is electrically stimulated, closely followed by direct TMS stimulation to the contralateral motor cortex. The timing between the two stimuli is adjusted such that the afferent signal from the forearm arrives in the motor cortex via somatosensory cortex in sync with the delivery of the TMS pulse. Providing the TMS pulses for 90 stimulus pairs over a half hour significantly increases subsequent MEP amplitudes for a period of 30 to 60 minutes, and the effects of PAS (rapid evolution, persistence, time-sensitive, and reversible) resemble LTP, which have been modeled by a Hebbian synaptic mechanism. ${ }^{12,13}$ A more direct demonstration of LTP was evidenced using event-related electroencephalographic (EEG) potentials (ERPs). ${ }^{8}$ A 5-Hz rTMS protocol was used that was a close approximation to the traditional LTP paradigm. The motor cortex was targeted and the typical potentiation of MEP was found. Topographic EEG was recorded and ERPs timelocked to TMS stimuli were potentiated.

In summary, TMS produces neuroplastic effects that are LTP- and LTD-like in nature, and possibly in mechanism. One caveat raised in a consensus report on TMS and plasticity suggested that, unlike the PAS paradigm, the evidence is weak with regard to the mechanisms of effects of rTMS as used to treat neuropsychiatric illnesses, and that if it is to continue to be used for treatment, investigations into mechanism should become a priority. ${ }^{11}$ 


\section{TMS in geriatric disorders}

While the mechanisms of longer-lasting effects of TMS are still under investigation, there is a large body of evidence in the neuropsychiatric arena that TMS does indeed result in neuroplastic changes that can improve therapeutic outcomes (eg, decrease depression severity). Much of the clinical research with TMS has been conducted in adult cohorts, but it has also been extended to elderly adults. For instance, investigations have examined the effects of TMS in geriatric patients with stroke, Alzheimer's disease, and MDD.

\section{Post-stroke neurorehabilitation}

Neuroplastic changes secondary to physical therapy for the treatment of stroke have been measured with TMS. For example, a map of the underlying cortical representation of a muscle can be made by measuring the amplitude of the MEPs resulting from TMS pulses applied to a grid of select areas over the motor cortex. These cortical representation maps can then be compared to observe cortical reorganization as a result of behavioral motor training exercises. ${ }^{14}$ In addition, MEPs evoked by TMS can be used to measure inter- and intrahemispheric cortical inhibition and excitation, which can also be used to index neuroplastic changes induced by various therapies used in post-stroke neurorehabilitation. ${ }^{15,16}$

Aside from measuring effects of physical therapy, TMS can be used to directly facilitate its neuroplastic and therapeutic effects. For example, in a study by Kim et al, ${ }^{17}$ the investigators applied trains of $10 \mathrm{~Hz}$ rTMS to patients with hemiparesis who alternately completed practice trials of a sequential finger motor task in which they reproduced 7-digit sequences of the numbers 1 to 4 with button presses. Over the course of a session, patients who received active rTMS, relative to those who received sham, showed significantly improved movement accuracy and speed. ${ }^{17}$ Such TMS facilitation has been repeatedly demonstrated for neurorehabilitation after stroke..$^{15,18-22}$ Importantly, a recent study that used $5 \mathrm{~Hz}$ rTMS in conjunction with physical therapy across ten sessions resulted in better clinical improvement above physical therapy alone that were sustained over a 12 -week naturalistic observational follow-up period. ${ }^{23}$ This provided strong evidence for the potential clinical usefulness of TMS in post-stroke recovery.
Beyond recovery of motor function, TMS may also aid in recovery of language functions in aphasia. In patients with left frontal lesions, ten sessions of $1 \mathrm{~Hz}$ rTMS applied to the unaffected hemisphere over 2 weeks resulted in improved picture naming. ${ }^{24}$ This clinical benefit has been replicated a number of times ${ }^{25,26}$ and has been found to persist for at least 2 months after acute treatment. ${ }^{27}$ The improvements from $1 \mathrm{~Hz}$ rTMS have been interpreted to result from inhibition of right hemisphere contralesional regions and possible excitation of undamaged left hemisphere cortex that allows for remapping of language function in perilesional areas. ${ }^{24,28}$

\section{Dementia and age-related cognitive decline}

Changes in intracortical inhibition and excitation shown by TMS could serve to distinguish mild cognitive impairment (MCI) from Alzheimer's disease (AD), ${ }^{29-31}$ early stages of $\mathrm{AD}$, and frontotemporal dementia, ${ }^{32}$ subcortical vascular dementia, ${ }^{33}$ and normal and abnormal aging in general. ${ }^{34}$ Prior research with TMS has found that AD is associated with increased motor cortical excitability. ${ }^{35-41}$ This hyperexcitability may serve as an indicator for a compensatory mechanism of cortical reorganization in which secondary motor areas (eg, premotor and supplementary motor cortex) are recruited to help execute movements. ${ }^{37,41}$ As such, TMS can play an important role in enhancing the incremental validity of the neurodiagnostic evaluation process for patients with suspected abnormal cognitive.

Besides functioning as a diagnostic tool, there are indications that TMS may directly act to modulate cortex to improve memory function in elderly patients. For example, Sole-Padulles et $\mathrm{al}^{42}$ found that $5 \mathrm{~Hz}$ rTMS applied to the prefrontal cortex significantly enhanced performance on a face-name memory task in 40 subjects with impaired memory who received active but not sham rTMS. Also, subjects who received active rTMS showed activity in the occipital and prefrontal regions in postcompared with prefunctional magnetic resonance imaging (fMRI) that was recorded while they performed the memory task. This finding suggested that rTMS aided the recruitment of an additional neural network that led to enhanced performance. In a study of 15 patients with probable AD, $0.6 \mathrm{~s}$ trains of $20 \mathrm{~Hz}$ rTMS was delivered to the left or right dorsolateral prefrontal cortex, during while the patients were completing a picture naming task. Active, but not sham rTMS resulted in improved 


\section{Treatment research}

accuracy on the task..$^{43}$ This result was replicated in a cohort of 24 patients with probable AD, with the addition that in patients with more severe $\mathrm{AD}$, the rTMS also enhanced accuracy in naming objects as well as actions. ${ }^{44}$ The same group of investigators later demonstrated that rTMS enhanced the language neuronal network (via stimulation of left dorsolateral prefrontal cortex) based on improved performance on a sentence comprehension task that was sustained for up to 8 weeks. ${ }^{45}$

\section{Depression in the elderly}

Major depression is a common neuropsychiatric disease that afflicts elderly adults. ${ }^{46}$ For adults, research has found TMS to be efficacious in reducing depressive symptoms and was approved by the US FDA in 2008 for the treatment of MDD. The approved treatment consists of 6 weeks of $10 \mathrm{~Hz}$ rTMS sessions applied to the left dorsolateral prefrontal cortex. Since MDD is a prevalent condition among the elderly and its treatment within this population can be challenging due to medication complications (eg, drug-drug interaction, medication sensitivity), TMS is being explored as an antidepressant strategy. However, a number of studies have not found TMS to have similar beneficial effects in elderly patients as has been reported in younger adult populations. For instance, one open-label study reported that $56 \%$ of young depressed patients responded to rTMS of the left prefrontal cortex, whereas only $23 \%$ of elderly patients responded with the same treatment. ${ }^{47}$ Also, three randomized controlled clinical trials found no antidepressant benefit from rTMS in elderly patients, ${ }^{48-50}$ and a metanalysis of five clinical TMS trials (four randomized, double-blind, one open-label) found age to be a negative predictor of therapeutic benefit. ${ }^{51}$ These findings have led some to conclude that rTMS was ineffective for the treatment of depression in the elderly. ${ }^{52} \mathrm{~A}$ more recent study also reported only modest antidepressant effects for rTMS in an elderly cohort. ${ }^{53}$

The null finding of rTMS in treating MDD in elderly adults may be related to the increased scalp-to-cortex distance in that population. ${ }^{47}$ This was suggested because motor and prefrontal cortex atrophy occurs in elderly subjects. ${ }^{54}$ Atrophy inevitably increases scalp to cortical distance, likely resulting in the need for a stronger stimulus intensity, since magnetic field strength decreases exponentially as distance increases. Two subsequent studies that used structure MRI methods found rela- tionships between the antidepressant effect of TMS and scalp-to-cortex distance. ${ }^{55,56} \mathrm{Nahas}$ et $\mathrm{al}^{54}$ tested these ideas by adjusting the TMS dosage by the distance to prefrontal cortex in a group of older adults, which resulted in a higher rate of responders than in earlier studies. One way to compensate for the scalp-to-cortex distance to improve antidepressant benefit would be to use a more powerful stimulus, such as used in magnetic seizure therapy (see below).

\section{TMS and plasticity with aging}

As the depression research suggests, changes with aging may mediate the association between TMS stimulation and cortical activity, as cortical atrophy with aging can reduce the delivered dosage of magnetic stimulation. Independent of distance issues, preclinical models suggest that aging can also reduce the ability of TMS to induce plasticity. Aging decreases the flexible responsiveness of neural systems. For example, LTP induced in hippocampal slices decays faster in older relative to younger rats. ${ }^{57}$ Preclinical research has shown that many factors, including changes in dendritic morphology, cellular connectivity, calcium ion regulation, and gene expression, can result in decreased plasticity. ${ }^{58}$ This decrease in plasticity can also be directly observed using TMS. For instance, one study found that 5 days of TMS (2s $25-\mathrm{Hz}$ trains) enhanced subsequent hippocampal LTP induction in younger but not older rats. ${ }^{59}$ Moreover, TMS reduced the amount of inhibition induced by frequency dependent stimulation in young but not older animals, suggesting that the TMS effects were dependent on age. In humans too, it has been hypothesized that plasticity decreases across the life span. ${ }^{60}$ Using one form of highly efficacious TMS ( $\theta$ burst stimulation [TBS]) that has been linked to LDP-like modulation, it was found that inhibition produced by TBS in the motor cortex decreased with age. ${ }^{61}$ Similarly, there was weakened TMS induced plasticity with age, and little or no enhancement of MEPs in older adults with the PAS technique. ${ }^{62,63}$ Cognitive, sensory, and motor functions depend on distributed cortical and subcortical networks, and their connectivity may be weakened with aging. Consequently, the loss of plasticity leads to alterations in neural network dynamics that ultimately play a role in cognitive, sensory and motor deficits with old age. ${ }^{58}$ In conjunction with neuroimaging methods, TMS can be used to study these age-related changes in connectivity. For example, in a 
study that combined rTMS and positron emission tomography (PET), $1 \mathrm{~Hz}$ rTMS to the premotor cortex was found to modulate activity in an extensive motor network that included the premotor, prefrontal, insular, and parietal cortices, thalamus, striatum, and cerebellum in young subjects. However, effective connectivity with brain regions distant from the point of stimulation was diminished in elderly subjects. ${ }^{64}$ In another study, subjects performed a working memory task where they were required to remember faces and ignore scenes (and vice versa).$^{65}$ Through fMRI and EEG recordings when young subjects performed this task, it was found that, via prefrontal top-down control, sensory processing activity was modulated in fusiform and parahippocampal/lingual gyrus for face and scene stimuli, respectively. Responses were enhanced to attended stimuli and inhibited to interfering stimuli. For elderly subjects though, they did not show inhibitory effects, suggesting that there is increased difficulty suppressing distracting information with age. The inhibitory deficits observed in elderly adults can be simulated in young adults through application of rTMS to the prefrontal cortex which disrupts the top-down processing and behavioral performance. ${ }^{65,66}$

While the effectiveness of plasticity mechanisms decreases with age, the brain may compensate to some degree for loss of function through reorganization. For example, as mentioned above, motor cortex hyperexcitability seen with TMS may reflect compensatory activity in the premotor cortex and SMA to aid voluntary movements. ${ }^{37,41}$ In addition, brain imaging has suggested two possible forms of reorganization in working and episodic memory, cross hemisphere recruitment (hemispheric asymmetry reduction in older adults: HAROLD $)^{67}$ and a posterior-anterior shift in activation with aging. ${ }^{68} \mathrm{~A}$ recent study that used $20 \mathrm{~Hz}$ rTMS to disrupt verbal memory processing in left and right prefrontal cortex in elderly subjects provided causal evidence in favor of HAROLD-type compensatory processing. ${ }^{69}$ In general, TMS may aid both the understanding of compensatory reorganization in aging, and also in actively aiding remapping of function, as seen in recovery from stroke. ${ }^{27}$

\section{A model paradigm for fMRI-guided rTMS in enhancing plasticity in cognitive decline}

Cell death predominates as the reason for cognitive deficits associated with $\mathrm{AD}$, which may be related to synaptic changes in otherwise intact neural circuitry that leads to decline in normal aging. ${ }^{70}$ The application of TMS to the appropriate circuitry (guided by brain imaging) may be a useful strategy to strengthen aging circuitry and increase its resilience. However, while longlasting improvements using TMS in post-stroke rehabilitation and in $\mathrm{AD}$ cited above are encouraging in this regard, there have been to date no attempts to use TMS to improve cognitive decline in the elderly. On the other hand, TMS has been reported to enhance performance in young adults in a number of tasks affected by aging including choice reaction time, ${ }^{71}$ picture naming, ${ }^{72}$ mental rotation of 3-D objects, ${ }^{73}$ recognition memory, ${ }^{74}$ and working memory. ${ }^{75}$ The performance enhancement caused by TMS in these studies was short-lived and lasted on average between 10 and 60 minutes. ${ }^{4,76}$

There has been some indication that increasing the duration of TMS stimulation may increase the subsequent duration of beneficial cognitive effects. ${ }^{4}$ Moreover, as reported above, repeated sessions of TMS can result in durable improvements in motor movement post-stroke, in language function in aphasia, in word recall in $\mathrm{AD}$, and in mood in depression. Likewise, repeated TMS sessions may also prolong the duration of cognitive benefits. ${ }^{5}$ In addition, beneficial cognitive effects associated with TMS might be prolonged via the interaction of the stimulation with native cortical mechanisms of plasticity while subjects perform a cognitive task. ${ }^{77}$ Long-lasting benefits incorporating such an approach have been shown in recovery from stroke, ${ }^{22,23,27}$ including a successful test of Hebbian-based training and TMS. ${ }^{78}$

Over a series of studies, we tested whether we could use TMS to boost resilience in a neural network. We did this by creating a temporary working memory (WM) deficit in healthy young adults through sleep deprivation, and attempting to reverse the deficit with TMS. Eighteen subjects (ages 18 to 35 ) completed a delayed-match-tosample (DMS) WM task, in which a set of 1,3, or 6 letters was shown to the subject for $3 \mathrm{sec}$. After a 7 -sec delay period, a probe letter was presented for $3 \mathrm{sec}$. The subjects made a differential button press to indicate whether or not the probe letter was included in the study set. Initially, sophisticated covariance techniques were used on fMRI data to determine a cortical network activated by a working memory task that was sensitive to sleep deprivation (SD). ${ }^{79}$ Subjects underwent fMRI while performing the DMS task before and immediately after 48 hours of sustained wakefulness (verified by continuous EEG monitoring). Following sleep deprivation, 


\section{Treatment research}

reaction time (RT) and RT variability increased from baseline levels, along with a drop in accuracy, and the percentage of non-responses (lapses) increased from $0 \%$ to $30 \%$. Ordinal Trends Analysis (OrT), a newly-developed multivariate covariance analysis ${ }^{80,81}$ was applied to the data from the probe period of the task and identified an activation pattern whose expression decreased with sleep deprivation in 17 of 18 subjects. Regions that decreased their activation were in parietal (Brodmann's area [BA] 7 and 40), temporal (BA 37,38, and 39), and occipital (BA 18 and 19) lobes. Decreases in pattern expression were correlated with reductions in recognition accuracy, increased intraindividual variability in RT, and increased lapsing. Thus, using OrT analysis we found a performance-related network whose expression decreased across two days of sleep deprivation.

As a second step, we systematically explored rTMS parameters to optimize modulation of WM performance. ${ }^{75}$ Active and sham rTMS at 1,5 , or $20 \mathrm{~Hz}$ was applied to either the left dorsolateral prefrontal or midline parietal cortex during the retention phase of the DMS task in 19 healthy young subjects. The cortical sites were selected from initial analyses of fMRI data using the DMS task in non-sleep-deprived subjects. Study set sizes of one and six letters were used. Only $5 \mathrm{~Hz}$ stimulation to the parietal site resulted in a significant decrease in RT without a corresponding decrease in accuracy. This finding was replicated in a second study in which $5 \mathrm{~Hz}$ rTMS at the parietal site was applied during the retention phase or during presentation of the recognition probe in 21 young subjects. Relative to sham, active rTMS resulted in significantly improved RT only in the retention phase. These results suggested that TMS could improve WM performance, but only in a manner that is specific to the timing of stimulation relative to performance of the task, to the targeted cortical region based on fMRI data, and to stimulation frequency.

Building on the knowledge obtained in those studies, fMRI-guided rTMS was then used to remediate cognitive performance in sleep-deprived individuals. The subjects benefited proportionally to the level of their deficit in the expression of the previously identified network. ${ }^{82}$ This suggested that TMS had modulated a cortical network critical to the WM task in a way that improved its resilience to SD. In 15 participants who had been sleepdeprived for two days, rTMS was applied at $5 \mathrm{~Hz}$ during the retention phase of the DMS task. The target sites for stimulation was based on the fMRI network associated with sleep deprivation-induced performance impairments in this task. ${ }^{79}$ Three stimulation sites were chosen and included the upper left occipital and midline parietal cortices, which were parts of this fMRI network, and the lower left occipital cortex, which was adjacent to the first occipital site, but outside the fMRI identified network. Stimulation with rTMS on the upper occipital site resulted in decreased sleep-induced RT deficit without a corresponding decrease in accuracy. Stimulation of the other two sites did not produce such benefits. The subjects underwent fMRI scanning while they performed the task before and after sleep deprivation. The degree of performance enhancement with upper occipital rTMS correlated with the degree to which each individual failed to sustain activation of the fMRI network. A subset of participants $(\mathrm{N}=11)$ performed the same rTMS procedure after recovering from sleep deprivation, and no effects were found for rTMS. These results demonstrated that rTMS applied to the superior occipital cortex, part of a WM network sensitive to SD, specifically reduced the adverse effects of SD on WM performance. We suggested that a proposed mechanism known as "post-tetanic facilitation," which posits that TMS delivered just prior to task-related neural processing increases cortical excitability in a way that can enhance performance under some conditions, may have been responsible for the facilitation effect with occipital stimulation.

In the final step, we utilized two proposed methods of extending rTMS effects (multiple rTMS sessions and simultaneous task performance and application of targeted rTMS) to a new group of SD subjects and found that those who received active rTMS did not show the typical cognitive effects (eg, slowing, lapsing) of SD on WM. ${ }^{83}$ Five Hz rTMS was applied to the left occipital site while subjects performed the DMS task during four sessions over the course of 48 hours of sleep deprivation, with performance assessed at the beginning and end of sleep deprivation. Twenty-seven subjects (13 received active TMS, 14 sham) completed the study protocol. Another twenty (10 received active TMS, 11 sham) nonsleep-deprived subjects were included and served as controls. At the end of the SD period, sham SD subjects exhibited degraded performance on the WM task, with slowed RT and lapsing typical of SD. In contrast, those who received active rTMS performed similarly to the non-SD controls, and exhibiting a speeding up of RT attributed to practice in the non-SD controls, and a sig- 
nificantly reduced lapsing rate. Importantly, the active SD group showed rTMS-induced facilitation of DMS performance a full 18 hours after the last rTMS session. All subjects were also tested on a number of other behavioral tasks; however, the active and sham SD groups showed equivalent performance. This suggested that the effects of rTMS were specific to the DMS task. Two cortical regions distinguished the active and sham SD groups. The sham group had greater fMRI activation in the right parahippocampal gyrus, while the active group had greater activation in a cortical region directly beneath where the coil had been placed in the TMS sessions.

The results of the last step indicated that multiple sessions of rTMS applied concurrently with DMS task performance over the course of SD worked to generate sufficient neuroplasticity and subsequent neural changes in the distributed circuitry involved in processing the DMS task. This enabled superior cognitive working memory performance in subjects who received active rTMS a day after the last rTMS session, presumably long after the acute action of rTMS wore off at the local site of stimulation. As such, we suggest that fMRI-guided rTMS increased the resilience of neural circuitry specifically involved in WM to prevent the full impact of SD. The TMS paradigm used here may be a useful tool to help remediate specific cognitive deficits by strengthening networks vital to particular processing but weakened by the effects of age.

\section{Magnetic seizure therapy}

At subconvulsive levels, TMS has been found to have modest antidepressant effects, particularly in elderly populations. One way to overcome this limitation would be through increasing its dosage into the convulsive range, given the superior antidepressant potency of electroconvulsive therapy (ECT). While ECT is unparalleled in efficacy even in elderly populations, its risk of amnesia remains a limiting factor, particularly in elderly populations. The rationale behind magnetic seizure therapy (MST) is to preserve the efficacy of ECT while reducing its risk of amnesia through enhanced focality offered by magnetic stimulation. ${ }^{84,85}$ When using subconvulsive TMS, the accidental induction of a seizure would be deemed an adverse effect, but under controlled conditions in a patient under anesthesia, the resultant seizure could confer robust antidepressant properties as seen with ECT.
The conceptualization of MST was based on combining the unique characteristics of TMS and ECT, ${ }^{86,87}$ that is, the use of magnetic pulses that can pass unimpeded through the scalp and skull of the former, to generate tonic-clonic seizure activity with known antidepressant activity of the latter. Moreover, TMS has been found to have neurocognitive advantages in that it has no known cognitive adverse effects when used to treat MDD, ${ }^{88}$ has been shown to enhance cognitive abilities, ${ }^{89}$ and has been found to be beneficial for neurorehabilitative paradigms. ${ }^{90}$ Thus, the objectives in developing MST are to maximize antidepressant benefit and either spare adverse cognitive effects, or if possible, improve cognitive abilities that are impacted by MDD. ${ }^{84,91}$

\section{Neurophysiological properties of magnetic seizure therapy}

Computational ${ }^{92,93}$ and preclinical studies ${ }^{94-96}$ have well characterized the neurophysiological properties of MST. The MST stimulus pulse is a dampened cosine shape in the ultra-brief wave form range that efficiently results in neuronal excitation ${ }^{96}$ with minimal electrical volume in cortical regions. ${ }^{93}$ Induction of the electric field and cerebral seizure activity with MST tends to have limited spatial distribution that regulates ictal expression, and is dependent upon a combination of MST technical parameters (eg, frequency, stimulus duration) and coil type and orientation. ${ }^{96}$ This observation was reproduced in a preclinical study that found electroconvulsive shock (ECS; bilateral electrode placement) produced more robust ictal expression and greater postical suppression on $\alpha, \beta$, and $\theta$ frequencies relative to MST $(50 \mathrm{~Hz}$, bilateral seizure induction).$^{94}$ However, both conditions showed similar ictal expression and postictal suppression of the delta frequency. A follow-up study by Cycowicz ${ }^{95}$ that compared ECS and MST administered with $100 \mathrm{~Hz}$ found the former produced greater ictal power in all frequencies $(\alpha, \beta, \delta, \theta)$, which correlated with decreased processing speed on a neurocognitive task of orientation. Regarding postical activity, all frequencies with the exception of showed greatly reduced magnitude of expression during ECS relative to MST. This was one of the first studies to correlate the neurophysiological characteristics to cognitive function, substantiating that different modes of convulsive induction do indeed confer different cognitive phenotypes. In clinical studies, MST has been found have delayed ictal 


\section{Treatment research}

EEG activity and similar rates of motor and EEG ictal activity. ${ }^{97,98}$ This is in stark contrast to ECT, which shows quick onset of ictal EEG expression that exceeds motor seizure activity. ${ }^{99,100}$

\section{Neurocognitive functioning and magnetic seizure therapy}

Resultant from its neurophysiological properties, MST spares penetrance to those cortical regions, particularly the hippocampus and its connectivity to the prefrontal cortices, responsible for cognitive functioning. In a preclinical model, it was demonstrated that MST did not produce neuropathological lesions, nor did it result in significant glial fibrillary acidic protein immunoreactivity in the superior frontal gyrus, hippocampal CA1 pyramidal layer, or the dentate gyrus molecular layer. ${ }^{101}$ Moreover, Dwork et al ${ }^{102}$ showed that MST did not impact the neurons or glia volume and density in the hippocampus (CA1 and CA2 regions) and frontal cortex.

The nonsignificant impact of MST on temporal structures has been observed in preclinical models that showed preservation, and in some cases, improved performance on neurocognitive tasks. ${ }^{103-105}$ Moscrip et $\mathrm{al}^{104}$ found no change in neurocognitive performance before and after 50-Hz MST, and Spellman et a $\mathrm{l}^{105}$ observed similar findings with $100 \mathrm{~Hz}$ MST. Interestingly, two of the subjects in the latter study that were also in the former showed improved performance on a measure of learning and memory suggesting a possible practice effect despite treatment with MST. This may represent the preservation of a strategy that the subjects developed in the first study to solve the neurocognitive task. For example, we found that stereotypy, a component cognitive process/strategy based on repetitive sequential selection of a correct spatial pattern sequence, was preserved in subjects after MST, and resulted in their increased accuracy on a spatial working memory task. ${ }^{103}$ However, when administered ECS, subjects showed decreased stereotypy and poorer accuracy on the same spatial working memory measure. Thus, MST allows for the maintenance of component cognitive processes/strategies, which are integral to higher order cognitive functions. Indeed, neuropsychologic research with healthy human subjects has found strong associations between cognitive strategies and neurocognitive outcome. Importantly, on commonly used neuropsychologic measures (eg, digit span, category flu- ency), strategy was more strongly associated with performance than were other demographic factors such as age and education. ${ }^{106}$

\section{Antidepressant activity of magnetic seizure therapy}

Although still in developmental phases, controlled clinical case reports and series, and one randomized control trial have found MST to have antidepressant benefits in patients with MDD or bipolar disorder. Four case reports that varied in methodologic design through use of various coil types (eg, round, butterfly, figure-of-eight), dosing parameters (eg, between $50 \mathrm{~Hz}$ and $100 \mathrm{~Hz}$ stimulation; 200 to 1000 pulses) and administration of number of treatment sessions (eg, four to twelve) found patients maintained global cognitive abilities, had rapid rates of reorientation recovery, and had corresponding decreased depression severity. ${ }^{85,107-109}$ Two case series showed similar results in patients with MDD. ${ }^{110,111}$ In the first, only two MST sessions (provided up to $60 \mathrm{~Hz}$ with multiple coil types) were administered in the context of an acute ECT course. ${ }^{110}$ Both treatments resulted in similar decreases in depression severity, but only in the MST sessions did patients show quick orientation recovery and preservation of multiple cognitive abilities including processing speed, and simple attention and memory. In the second case series, which followed a similar design as the first, 11 patients received at least one MST session (provided at $100 \mathrm{~Hz}$ for 10 seconds with a round coil). ${ }^{111}$ The study found that relative to ECT, patients showed quicker recovery of orientation that was shorter on average by approximately 15 minutes. To date, a randomized controlled trial found MST (delivered with twin coil, $100 \mathrm{~Hz}$, up to 600 pulses) and ECT (delivered with 0.5 brief pulse wave form, right unilateral electrode placement) to be comparable with regard to antidepressant efficacy and neurocognitive safety, with the exception that patients in the MST relative to those in the ECT group showed earlier time to recovery and reorientation, and no adverse effects (eg, headache, nausea, muscle pain). ${ }^{97}$ The rates of response and remission for MST exceeds those reported for TMS (ie, $15 \%$ remission rate) in the treatment of MDD, ${ }^{112,113}$ but are less than those reported for ECT (eg, greater than $80 \%$ for acute course). ${ }^{14,115}$ With continued development, MST may be able to match the response the remission rates of ECT, but this will only be important should it also maintain its neurocognitive safety or possible cognitive enhancement properties. 


\section{Applications of magnetic seizure therapy in vulnerable populations}

As a hybrid between TMS and ECT, MST is being developed as a neurotherapeutic strategy for the treatment of major affective disorders. Converging preclinical and clinical evidence suggests that MST has benign cognitive effects, and possibly could improve cognitive abilities. ${ }^{91}$ As such, MST may have applications in vulnerable populations with neuropsychiatric diseases including patients who are elderly or have traumatic brain injury (TBI) or dementia. Also, given recent findings that TMS does not impact cognitive functioning in children and adolescents with MDD, MST too could serve a role if it is found to be safe in this cohort (Well et al, personal communication). In elderly adults and those with TBI or dementia, MST may be able to improve mood-related disorders and cognitive abilities, or at the very least, spare impacting cognitive abilities, thereby preventing long-term adverse cognitive effects. Neurorehabilitative paradigms may benefit from MST. The comorbidity of MDD with other neuropsychiatric diseases, particularly traumatic brain injury (TBI), ${ }^{116}$ may prohibit the successful implementation of neurorehabilitative paradigms. While ECT has been found to be useful to treat MDD in TBI cohorts, the deleterious cognitive affects could minimize the immediate and beneficial use of neurorehabilitation. Hypothetically, MST and neurorehabilitation could be delivered concurrently such that the patient could experience decreased depression severity

\section{REFERENCES}

1. Wassermann EM, Lisanby $\mathrm{SH}$. Therapeutic application of repetitive transcranial magnetic stimulation: a review. Clin Neurophysiol. 2001;112:1367-1377.

2. Luber B, Peterchev A, Nguyen T, Sporn A, Lisanby SH. Application of TMS in psychophysiological studies. In: Cacioppo LG, Tassinary GG. Berntson JT, eds. Handbook of Psychophysiology. 3rd ed. New York, NY: Cambridge University Press; 2007.

3. Fitzgerald PB, Fountain S, Daskalakis ZJ. A comprehensive review of the effects of rTMS on motor cortex excitability and inhibition. Clin Neurophysiol. 2006;117:2584-2596.

4. Peinemann A, Reimer B, Loer C, Quartarone A, Munchau A, Conrad B, Siebner HR Long-lasting increase in corticospinal excitability after 1800 pulses of subthreshold $5 \mathrm{~Hz}$ repetitive TMS to the primary motor cortex. Clin Neurophysiol. 2004;115:1519-1526.

5. Thut G, Pascual-Leone A. A review of combined TMS-EEG studies to characterize lasting effects of repetitive TMS and assess their usefulness in cognitive and clinical neuroscience. Brain Topogr. 2009;22:219-232.

6. Bliss TV, Collingridge GL, Morris RG. Introduction. Longterm potentiation and structure of the issue. Philos Trans R Soc Lond B Biol Sci. 2003;358:607-611.

7. Bliss TV, Lomo T. Long-lasting potentiation of synaptic transmission in the dentate area of the anaesthetized rabbit following stimulation of the perforant path. J Physiol. 1973;232:331-356. while simultaneously benefiting from improved cognitive abilities. Similar types of strategies are employed with combined TMS and neurorehabilitative programs. Extensive work with MST is required to first empirically validate its inclusion in the antidepressant psychiatric armamentarium, and then to further its involvement in therapeutic strategies for vulnerable populations. Continued translational investigations will provide answers to open questions at this time including the effects of MST on neurogenesis, the relationship between neurogenesis and neurocognitive and clinical outcome, and the linkage to functionality.

\section{Conclusion}

Through its function as a probe of cortical activity, modulator of neuroplasticity, indicator of brain and behavior causal relationships, and treatment of neuropsychiatric disease, TMS is a powerful tool for neuroscientific research and clinical applications. While the past few decades have aided its development, the upcoming decades will inform its refinement and take advantage of its multifunctional properties. Indeed, subconvulsive TMS and convulsive MST have been found to have beneficial neurocognitive effects, which substantiate their continued development and employment in the neuropsychiatric arena.

Acknowledgments: This review was funded in part by NIH grants $\mathrm{K} 23$ MH087739 and K01 AG031912, and the Stanley Medical Research Foundation.

8. Esser SK. Huber R, Massimini M, Peterson MJ, Ferrarelli F, Tononi G. A direct demonstration of cortical LTP in humans: a combined TMS/EEG study. Brain Res Bull. 2006;69:86-94.

9. Touge T, Gerschlager W, Brown P, Rothwell JC. Are the after-effects of low-frequency rTMS on motor cortex excitability due to changes in the efficacy of cortical synapses? Cli. Neurophysiol. 2001;112:2138-2145.

10. Muller-Dahlhaus F, Ziemann U, Classen J. Plasticity resembling spiketiming dependent synaptic plasticity: the evidence in human cortex. Frontiers Synaptic Neurosci. 2010;2:34.

11. Ziemann U, Paulus W, Nitsche MA et al. Consensus: motor cortex plasticity protocols. Brain Stimulation. 2008;1:164-182.

12. Stefan K, Kunesch E, Cohen LG, Benecke R, Classen, J. Induction of plasticity in the human motor cortex by paired associative stimulation. Brain. 2000;123:572-584.

13. Wolters A, Sandbrink F, Schlottmann A. A temporally asymmetric Hebbian rule governing plasticity in the human motor cortex. J Neurophysiol. 2003;89:2339-2345.

14. Liepert J, Graef S, Uhde I, Leidner O, Weiller C. Training-induced changes of motor cortex representations in stroke patients. Acta Neurol Scand. 2000;101:321-326.

15. Bashir S, Mizrahi I, Weaver K, Fregni F, Pascual-Leone A. Assessment and modulation of neural plasticity in rehabilitation with transcranial magnetic stimulation. PM R. 2010;2(suppl 2):S253-S268. 


\section{Treatment research}

\section{Aplicaciones de la estimulación magnética transcraneal y la terapia magneto convulsiva en el estudio y tratamiento de los trastornos relacionados con el envejecimiento cerebral}

La estimulación magnética transcraneal (EMT) puede emplearse para evaluar la función cortical y tratar enfermedades neuropsiquiátricas. La EMT ha demostrado efectos neuroplásticos similares a la potenciación a largo plazo y la depresión a largo plazo, y están en desarrollo aplicaciones terapéuticas para la recuperación post accidente cerebro vascular, la Enfermedad de Alzheimer y la depresión en personas de edad avanzada. En este artículo se discuten dos nuevas orientaciones de la investigación en EMT relevantes para el envejecimiento cerebral y la cognición. Inicialmente se presenta un paradigma para reforzar la reserva cognitiva, basado en la investigación de los autores en privación de sueño. Luego se discute el empleo de la terapia magneto convulsiva (TMC) para preservar funciones cognitivas que se afectan con la terapia electroconvulsiva convencional, y como una forma de aportar un tratamiento antidepresivo de mayor potencial cuando la EMT subconvulsiva ha demostrado una pobre eficacia en los ancianos. Si se considera que el refuerzo de la cognición es un objetivo del tratamiento o que se puede reducir la amnesia como efecto lateral, es que estas aproximaciones para el empleo de la EMT o la TMC merecen futuras exploraciones relacionadas con su potencial clínico.

\section{Stimulation magnétique transcrânienne et magnétoconvulsivothérapie dans l'étude et le traitement des troubles liés au vieillissement cérébral.}

La stimulation magnétique transcrânienne (TMS) peut être utilisée pour explorer la fonction corticale et traiter les maladies neuropsychiatriques. La TMS a montré des effets neuroplastiques analogues à ceux d'une potentialisation et d'une dépression à long terme, et des applications thérapeutiques sont en cours de développement dans la récupération post-AVC, la maladie d'Alzheimer et la dépression chez les sujets âgés. Dans cet article, nous analysons deux nouvelles directions de la recherche en TMS, pertinentes pour le vieillissement cérébral et la cognition. Nous introduisons tout d'abord un modèle d'une réserve cognitive qui se développe, basé sur notre recherche sur la privation de sommeil. Puis nous discutons de l'utilisation de la magnéto-convulsivo-thérapie (MCT) pour épargner les fonctions cognitives par rapport à l'électroconvulsivothérapie conventionnelle, et comme traitement antidépresseur plus puissant quand la TMS subconvulsive apparaît modérément efficace chez les sujets âgés. Que l'on considère l'amélioration de la cognition comme un but thérapeutique ou la diminution de l'amnésie comme un effet secondaire, la TMS et la MCT méritent d'être approfondies dans leur utilisation compte tenu de leur potentiel clinique.
16. Chen $R$, Cros D, Curra A et al. The clinical diagnostic utility of transcranial magnetic stimulation: Report of an IFCN committee. Clin Neurophysiol. 2008;119:504-532.

17. Kim $\mathrm{YH}$, You $\mathrm{SH}, \mathrm{Ko} \mathrm{MH}$, et al. Repetitive transcranial magnetic stimulation-induced corticomotor excitability and associated motor skill acquisition in chronic stroke. Stroke. 2006;37:1471-1476.

18. Khedr EM, Ahmed MA, Fathy N, Rothwell JC. Therapeutic trial of repetitive transcranial magnetic stimulation after acute ischemic stroke. Neurology. 2005;65:466-468.

19. Mansur CG, Fregni F, Boggio PS, et al. A sham stimulation-controlled trial of rTMS of the unaffected hemisphere in stroke patients. Neurology. 2005;64:1802-1804.

20. Takeuchi N, Chuma T, Matsuo Y, Watanabe I, Ikoma K. Repetitive transcranial magnetic stimulation of contralesional primary motor cortex improves hand function after stroke. Stroke. 2005;36:2681-2686.

21. Fregni F, Boggio PS, Valle AC, et al. A sham-controlled trial of a 5-day course of repetitive transcranial magnetic stimulation of the unaffected hemisphere in stroke patients. Stroke. 2006;37:2115-2122.
22. Wang R-Y, Tseng H-Y, Liao K-K, Wang C-J, Lai K-L, Yang Y-R. rTMS combined with task-oriented training to improve symmetry of interhemispheric corticomotor excitability and gait performance after stroke: a randomized trial. Neurorehab Neural Repair. 2012;26:222-230.

23. Emara TH, Moustafa RR, Elnahas NM. Repetitive transcranial magnetic stimulation at $1 \mathrm{~Hz}$ and $5 \mathrm{~Hz}$ produces sustained improvement in motor function and disability after ischaemic stroke. Eur J Neurol. 2010; 17:1203-1209. 24. Naeser MA, Martin PI, Nicholas M, et al. Improved picture naming in chronic aphasia after TMS to part of right Broca's area: an open-protocol study. Brain Lang. 2005;93:95-105.

25. Hamilton RH, Chrysikou EG, Coslett B. Mechanisms of aphasia recovery after stroke and the role of noninvasive brain stimulation. Brain Lang. 2011;118:40-50.

26. Schlaug G, Marchina S, Wan CY. The use of non-invasive brain stimulation techniques to facilitate recovery from post-stroke aphasia. Neuropsychol Rev. 2011; 21:288-301.

27. Naeser MA, Martin PI, Ho M, et al. Transcranial magnetic stimulation and aphasia rehabilitation. Arch Phys Med Rehabil. 2012;93(suppl 1):S26-S34. 
28. Fregni F, Pascual-Leone A. Technology insight: noninvasive brain stimulation in neurology-perspectives on the therapeutic potential of rTMS and tDCS. Nature Clin Practice Neurol. 2007;3:383-393.

29. Inghilleri M, Conte A, Frasca V, et al. Altered response to rTMS in patients with Alzheimer's disease. Clin Neurophysiol. 2006;117:103-109.

30. Julkunen $P$, Jauhiainen AM, Westeren-Punnonen $S$, et al. Navigated TMS combined with EEG in mild cognitive impairment and Alzheimer's disease: a pilot study. J Neurosci Methods. 2008;172:270-276.

31. Sakuma K, Murakami T, Nakashima K. Short latency afferent inhibition is not impaired in mild cognitive impairment. Clin Neurophysiol. 2007;118:1460-1463.

32. Pierantozzi M, Panella M, Palmieri MG, et al. Different TMS patterns of intracortical inhibition in early onset Alzheimer dementia and frontotemporal dementia. Clin Neurophysiol. 2004;115:2410-2418.

33. Bella R, Ferri R, Pennisi M, et al. Enhanced motor cortex facilitation in patients with vascular cognitive impairment- no dementia. Neurosci Lett. 2011;501:171-175.

34. Rossini PM, Rossi S, Babiloni C, Polich J. Clinical neurophysiology of aging brain: From normal aging to neurodegeneration. Prog Neurobiol. 2007;83:375-400.

35. Alagona G, Bella R, Ferri R. Transcranial magnetic stimulation in Alzheimer's disease: motor cortex excitability and cognitive severity. Neurosci Lett. 2001;314:57-60.

36. De Carvalho M, de Mendoza A, Miranda P, Garcia C, De Lourdes M. Magnetic stimulation in Alzheimer's disease. J Neurol. 1997;244:304-307.

37. Pepin JL, Bogacz D, De Pasqua V, Delwaide PJ. Motor cortex inhibition is not impaired in patients with Alzheimer's disease: evidence from paired transcranial magnetic stimulation. J Neurol Sci. 1999;170:119-123.

38. Pennisi G, Alagona G, Ferri R, et al. Motor cortex excitability in Alzheimer disease: one year follow-up study. Neurosci Lett. 2002;329:293296.

39. Di Lazzaro V, Oliviero A, Tonali PA, et al. Non-invasive in vivo assessment of cholinergic cortical circuits in $A D$ using transcranial magnetic stimulation. Neurology. 2002;59:392-397.

40. Di Lazzaro V, Oliviero A, Pilato F, et al. Motor cortex hyperexcitability to transcranial magnetic stimulation in Alzheimer's disease. J Neurol Neurosurg Psychiatry. 2004;75:555-559.

41. Ferreri F, Pauri F, Pasqualetti P, Fini R, Dal Forno G, Rossini PM. Motor cortex excitability in Alzheimer's disease: a transcranial magnetic stimulation study. Ann Neurol. 2003;53:102-108.

42. Sole-Padulles $C$, Bartres-Faz D, Junque $C$, et al. Repetitive transcranial magnetic stimulation effects on brain function and cognition among elders with memory dysfunction. A randomized sham-controlled study. Cereb Cortex. 2006;16:1487-1493.

43. Cotelli M, Manenti R, Cappa SF, et al. Effect of transcranial magnetic stimulation on action naming in patients with Alzheimer disease. Arch Neurol. 2006;63:1602-1604.

44. Cotelli M, Manenti R, Cappa SF, Zanetti O, Miniussi C. Transcranial magnetic stimulation improves naming in Alzheimer disease patients at different stages of cognitive decline. Eur J Neurol. 2008;15:1286-1292.

45. Cotelli M, Calabria M, Manenti R, et al. Improved language performance in Alzheimer disease following brain stimulation. J Neurol Neurosurg Psychiatry. 2011;82:794-797.

46. Husain MM, Rush A, Sackeim HA, Wisniewski SR, et al. Age-related characteristics of depression: A preliminary STAR * D report. Amer J Geriatr Psychiatry. 2005;13:852-860.

47. Figiel, GS, Epstein C, McDonald WM, et al. The use of rapid-rate transcranial magnetic stimulation (rTMS) in refractory depressed patients. J Neuropsychiatry Clin Neurosci. 1998;10:20-25.

48. Klein E, Kreinin I, Chistyakov A. Therapeutic efficacy of right prefrontal slow repetitive transcranial magnetic stimulation in major depression. Arch Gen Psychiatry. 1999; 56: 315-320.

49. Manes F, Jorge R, Morcuende M, Yamada T, Paradiso S, Robinson RG. A controlled study of repetitive transcranial magnetic stimulation as a treatment of depression in the elderly. Int Psychogeriatr. 2001;13:225-231.

50. Mosimann UP, Schmitt W, Greenberg BD, et al. Repetitive transcranial magnetic stimulation: a putative add-on treatment for major depression in elderly patients. Psychiatry Res. 2004;126:123-133.
51. Fregni F, Marcolin MA, Myczkowski M, et al. Predictors of antidepressant response in clinical trials of transcranial magnetic stimulation. Int $J$ Neuropsychopharmacol. 2005;9:1-14.

52. Frazer CJ, Christensen H, Griffiths KM. Effectiveness of treatments for depression in older people. Med J Aust. 2005;182:627-632.

53. Milev R, Abraham G, Hasey G, Cabaj JL. Repetitive transcranial magnetic stimulation for treatment of medication-resistant depression in older adults. J ECT. 2009;25:24-49.

54. Nahas Z, Li X, Kozel FA, et al. Safety and benefits of distance-adjusted prefrontal transcranial magnetic stimulation in depressed patients 55-75 years of age: a pilot study. Depress Anxiety. 2004;19:249-256.

55. Kozel FA, Nahas Z, deBrux C. How coil-cortex distance relates to age, motor threshold, and antidepressant response to repetitive transcranial magnetic stimulation. J Neuropsychiatry Clin Neurosci. 2000;12:376-384.

56. Mosimann UP, Marre SC, Werlen S, et al. Antidepressant effects of repetitive transcranial magnetic stimulation in the elderly: correlation between effect size and coil-cortex distance. Arch Gen Psychiatry. 2002;59:560-561.

57. Barnes CA, McNaughton BL. Physiological compensation for loss of afferent synapses in rat hippocampal granule cells during senescence. Physiol (Lond.) 1980;309:473-485.

58. Burke SN, Barnes CA. Neural plasticity in the ageing brain. Nature Rev Neurosci. 2006;7:30-40.

59. Levkovitz $Y$, Segal M. Aging affects transcranial magnetic modulation of hippocampal evoked potentials. Neurobiol Aging. 2001;22:255-263.

60. Pascual-Leone A, Freitas C, Oberman L, et al. Characterizing brain cortical plasticity and network dynamics across the age span in health and disease with TMS-EEG and TMS-fMRI. Brain Topogr. 2011;24:302-315.

61. Freitas $C$, Mondrago'n-Llorca H, Pascual-Leone A. Noninvasive brain stimulation in Alzheimer's disease: Systematic review and perspectives for the future. Exp Gerontol. 2011;46:611-627.

62. Fathi D, Ueki Y, Mimaa T, et al. Effects of aging on the human motor cortical plasticity studied by paired associative stimulation. Clin Neurophysiol. 2010;121:90-93.

63. Müller-Dahlhaus JF, Orekhov Y, Liu Y, Ziemann U. Interindividual variability and age-dependency of motor cortical plasticity induced by paired associative stimulation. Exp Brain Res. 2008;187:467-475.

64. Rowe JB, Siebner H, Filipovic SR, et al. Aging is associated with contrasting changes in local and distant cortical connectivity in the human motor system. Neurolmage. 2006;32:747-760.

65. Gazzaley A, D'Esposito M. Top-down modulation and normal aging Ann NY Acad Sci. 2007;1097:67-83.

66. Gazzaley A. Influence of early attentional modulation on working memory. Neuropsychologia. 2011:49:1410-1424.

67. Cabeza R, Daselaar SM, Dolcos F, Prince SE, Budde M, Nyberg L. Task-independent and task-specific age effects on brain activity during working memory, visual attention and episodic retrieval. Cereb Cortex. 2004;14:364-375.

68. Davis SW, Dennis NA, Daselaar SM, Fleck MS, Cabeza R. Que PASA? The posterior-anterior shift in aging. Cereb Cort. 2008:18:1201-1209.

69. Manenti R, Cotelli M, Miniussi C. Successful physiological aging and episodic memory: a brain stimulation study. Behav Brain Res. 2011;216:153-158. 70. Hof PR, Morrison JH. The aging brain: morphomolecular senescence of cortical circuits. Trends Neurosci. 2004;27:607-613.

71. Evers S, Bockermann I, Nyhuis PW. The impact of transcranial magnetic stimulation on cognitive processing: an event-related potential study. Neuroreport. 2001;12:2915-2918.

72. Walsh V, Ellison A, Battelli L, Cowey A. Task-specific impairments and enhancements induced by magnetic stimulation of human visual area V5. Proc Biol Sci. 1998;265:537-543.

73. Klimesch W, Sauseng, P, Gerloff, C. Enhancing cognitive performance with repetitive transcranial magnetic stimulation at human individual alpha frequency. Eur J Neurosci. 2003;17:1129-1133.

74. Kohler S, Paus T, Buckner RL, Milner B. Effects of left inferior prefrontal stimulation on episodic memory formation: a two-stage fMRI -rTMS study. J Cogn Neurosci. 2004;16:178-188.

75. Luber B, Kinnunen LH, Rakitin BC, Ellsasser R, Stern $Y$, Lisanby SH. Facilitation of performance in a working memory task with rTMS stimulation of the precuneus: Frequency and time-dependent effects. Brain Res. 2007;1128:120-129. 


\section{Treatment research}

76. Mottaghy FM, Gangitano M, Sparing R, Pascual-Leone A. Segregation of areas related to visual working memory in the prefrontal cortex revealed by rTMS. Cereb Cortex. 2002;12:369-375.

77. Thickbroom GW. Transcranial magnetic stimulation and synaptic plas ticity: experimental framework and human models. Exp Brain Res. 2007; 180:583-593.

78. Buetefisch C, Heger R, Schicks W, Seitz R, Netz J. Hebbian-type stimulation during robot-assisted training in patients with stroke. Neurorehab Neural Repair. 2011;25:645-655.

79. Habeck C, Rakitin BC, Moeller J, et al. An event-related fMRI study of the neurobehavioral impact of sleep deprivation on performance of a delayed-match-to-sample task. Cogn Brain Res. 2004;18:306-321.

80. Habeck C, Krakauer JW, Ghez C, et al. A new approach to spatial covariance modeling of functional brain imaging data: ordinal trends analysis. Neural Computation. 2005;17:1602-1645.

81. Moeller JR, Habeck C. Reciprocal benefits of mass-univariate and multivariate modeling in brain mapping: Applications to event-related functional MRI, H2 15O-, and FDG-PET. Int J Biomed Imaging. 2006;2006:79862, doi:10.1155/IJBI/2006/79862.

82. Luber B, Stanford AD, Bulow $P$, et al. Remediation of sleep-deprivation induced visual working memory impairment with $\mathrm{fMRI}$-guided transcranial magnetic stimulation. Cereb Cortex. 2008;18:2077-2085.

83. Luber B, Steffner J, Tucker A, et al. Extended remediation of SD-induced working memory deficits using fMRI-guided rTMS. Sleep. In press.

84. Lisanby SH. Update on magnetic seizure therapy: a novel form of convulsive therapy. J ECT. 2002;18:182-188.

85. Lisanby SH, Schlaepfer TE, Fisch H-U, Sackeim HA. Magnetic seizure therapy of major depression. Arch Gen Psychiatry. 2001;58:303-305.

86. Lisanby SH, Luber B, Finck AD, Schroeder C, Sackeim HA. Deliberate seizure induction with repetitive transcranial magnetic stimulation in nonhuman primates. Arch Gen Psychiatry. 2001;58:199-200.

87. Sackeim HA. Magnetic stimulation and ECT. Convulsive Therapy. $1994 ; 10: 255-258$.

88. Martis B, Alam D, Dowd SM, et al. Neurocognitive effects of repetitive transcranial magnetic stimulation in severe major depression. Clin Neurophysiol. 2003;114:1125-1132.

89. Guse B, Falkai P, Wobrock T. Cognitive effects of high-frequency repetitive transcranial magnetic stimulation: a systematic review. J Neural Transm. 2010;117:105-122.

90. Hummel FC, Cohen LG. Non-invasive brain stimulation: a new strategy to improve neurorehabilitation after stroke? Lancet Neurol. 2006;5:708-712. 91. McClintock SM, Tirmizi O, Chansard M, Husain MM. a systematic review of the neurocognitive effects of magnetic seizure therapy. Int Rev Psychiatry. 2011b;23:413-423.

92. Deng ZD, Lisanby SH, Peterchev AV. Effect of anatomical variability on neural stimulation strength and focality in electroconvulsive therapy (ECT) and magnetic seizure therapy (MST). Conference Proceedings-IEEE Engineering in Medicine and Biology Society. 2009;682-688.

93. Deng ZD, Lisanby SH, Peterchev AV. Electric field strength and focality in electroconvulsive therapy and magnetic seizure therapy: a finite element study. J Neural Eng. 2011;8:016007.

94. Cycowicz YM, Luber B, Spellman T, Lisanby SH. Differential neurophysiological effects of magnetic seizure therapy (MST) and electroconvulsive shock (ECS) in non-human primates. Clin EEG Neurosci. 2008;39:144-149.

95. Cycowicz YM, Luber B, Spellman T, Lisanby SH. Neurophysiological characterization of high-dose magnetic seizure therapy: comparisons with electroconvulsive shock and cognitive outcomes. J ECT. 2009;25:157-164. 96. Lisanby SH, Moscrip T, Morales O, Luber B, Schroeder C, Sackeim HA. Neurophysiological characterization of magnetic seizure therapy (MST) in non-human primates. Supp/ Clin Neurophysiol. 2003;56:81-99.
97. Kayser S, Bewernick BH, Grubert C, Hadrysiewicz BL, Axmacher N, Schlaepfer TE. Antidepressant effects, of magnetic seizure therapy and electroconvulsive therapy, in treatment-resistant depression. J Psychiatry Res. 2011;45:569-576.

98. White PF, Amos Q, Zhang Y, et al. Anesthetic considerations for magnetic seizure therapy: a novel therapy for severe depression. Anesthesia Analgesia. 2006;103:76-80.

99. Coffey CE, Lucke J, Weiner RD, Krystal AD, Aque M. Seizure threshold in electroconvulsive therapy (ECT) II. The anitconvulsant effect of ECT. Biol Psychiatry. 1995;37:777-788.

100. Coffey CE, Lucke J, Weiner RD, Krystal AD, Aque M. Seizure threshold in electroconvulsive therapy: I. Initial seizure threshold. Biol Psychiatry. 1995;37:713-720.

101.Dwork AJ, Arango V, Underwood M, et al. Absence of histological lesions in primate models of ECT and magnetic seizure therapy. Am J Psychiatry. 2004;161:576-578.

102. Dwork AJ, Christensen JR, Larsen KB, et al. Unaltered neuronal and glial counts in animal models of magnetic seizure therapy and electroconvulsive therapy. Neurosci. 2009;164:1557-1564.

103. McClintock SM, DeWind NK, Husain MM, et al. Disruption of component processes of spatial working memory by electroconvulsive shock but not magnetic seizure therapy. Int J Neuropsychopharmacol. In press.

104. Moscrip TD, Terrace HS, Sackeim HA, Lisanby SH. Randomized controlled trial of the cognitive side-effects of magnetic seizure therapy (MST) and electroconvulsive shock (ECS). Int J Neuropsychopharmacol. 2006;9:1-11. 105. Spellman T, McClintock SM, Terrace H, Luber B, Husain MM, Lisanby SH. differential effects of high-dose magnetic seizure therapy and electroconvulsive shock on cognitive function. Biol Psychiatry. 2008;63:1163-1170.

106. Cirulli ET, Attix DK, Smith PJ, et al. Contribution of pastimes and testing strategies to the performance of healthy volunteers on cognitive tests. Clin Neuropsychologist. 2011;25:778-798.

107. Hoy KE, Fitzgerald PB. Introducing magnetic seizure therapy: A novel therapy for treatment resistant depression. Aust N Z J Psychiatry. 2010;44:591-598. 108. Kayser S, Bewernick BH, Axmacher N, Schlaepfer TE. Magnetic seizure therapy of treatment-resistant depression in a patient with bipolar depression. J ECT. 2009;25:137-140.

109. Kosel M, Frick C, Lisanby SH, Fisch H-U, Schlaepfer TE. Magnetic seizure therapy improves mood in refractory major depression. Neuropsychopharmacol. 2003;28:2045-2048.

110. Lisanby SH, Luber B, Schlaepfer TE, Sackeim HA. Safety and feasibility of magnetic seizure therapy (MST) in major depression: randomized withinsubject comparison with electroconvulsive therapy. Neuropsychopharmacol. 2003;28:1852-1865.

111. Kirov G, Ebmeier KP, Scott AIF, et al. Quick recovery of orientation after magnetic seizure therapy for major depressive disorder. Brit J Psychiatry. 2008; 193:152-155

112. George MS, Lisanby SH, Avery D, et al. Daily left prefrontal transcranial magnetic stimulation therapy for major depressive disorder: a sham-controlled randomized trial. Arch Gen Psychiatry. 2010;67:507-516.

113. O'Reardon JP, Solvason HB, Janicak PG, et al. Efficacy and safety of transcranial magnetic stimulation in the acute treatment of major depression: a multisite randomized controlled trial. Biol Psychiatry. 2007;62:1208-1216. 114. Husain MM, Rush A, Fink M, et al. Speed of response and remission in major depressive disorder with acute Electroconvulsive therapy (ECT): a consortium for research in ECT (CORE) report. J Clin Psychiatry. 2004;65:485-491. 115. Kellner CH, Knapp RG, Petrides G, et al. Continuation electroconvulsive therapy vs pharmacotherapy for relapse prevention in major depression. Arch Gen Psychiatry. 2006;63:1337-1344.

116. Rapoport MJ. Depression following traumatic brain injury: epidemiology, risk factors and management. CNS Drugs. 2012;26:111-121. 